\title{
Molecular Basis of Argininemia

\author{
Identification of Two Discrete Frame-shift Deletions in the Liver-type Arginase Gene
}

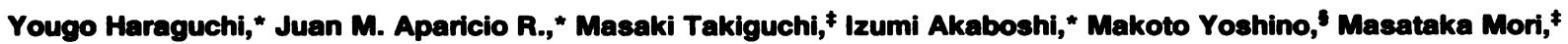
and Ichiro Matsuda*

*Department of Pediatrics and ${ }^{\ddagger}$ Institute for Medical Genetics, Kumamoto University Medical School, Kumamoto 860, Japan; and 'Department of Pediatrics and Child Health, Kurume University School of Medicine, Kurume 830, Japan

\begin{abstract}
Argininemia results from a deficiency of arginase (EC 3.5.3.1), the last enzyme of the urea cycle in the liver. We examined the molecular basis for argininemia by constructing a genomic library followed by cloning and DNA sequencing. Discrete mutations were found on two alleles from the patient, a product of a nonconsanguineous marriage. There was a four-base deletion at protein-coding region 262-265 or 263-266 in exon 3 that would lead to a reading-frame shift after amino acid residue 87 and make a new stop codon at residue 132. The other was a one-base deletion at 77 or 78 in exon 2 that would lead to a reading-frame shift after residue 26 and make a stop codon at residue 31. For confirmation, genomic DNAs from the patient and from her parents were amplified by the polymerase chain reaction method. The patient was shown to be a compound heterozygote, inheriting an allele with the four-base deletion from the father and the other allele with the one-base deletion from the mother. These data seem to be the first evidence of a case of argininemia caused by two different deletion mutations. (J. Clin. Invest. 1990. 86:347-350.) Key words: arginase deficiency - urea cycle - polymerase chain reaction - compound heterozygote $\bullet$ frame-shift mutation
\end{abstract}

\section{Introduction}

Arginase (EC 3.5.3.1) is the last enzyme of the urea cycle and catalyzes the conversion of arginine to urea and ornithine. Liver-type arginase is localized in the cytosol of the liver cells of ureotelic animals and in low amounts in red blood cells (1). Arginase isozyme(s) that differs from the liver-type enzyme in catalytic, molecular, and immunological properties, is present in the kidney, small intestine, brain, and lactating mammary gland (2-5). We isolated cDNA and genomic clones for rat (6, 7) and human (8-10) liver arginase and determined the structures. Human liver arginase consists of 322 amino acid residues (predicted $M_{\mathrm{r}}, 34,732$ ), and the gene is $11.5 \mathrm{~kb}$ long and divided into eight exons. Sparkes et al. (11) also isolated human liver arginase cDNA and assigned the gene to chromosome band 6q23.

Address reprint requests to Dr. Matsuda, Department of Pediatrics, Kumamoto University Medical School, 1-1-1 Honjo, Kumamoto 860, Japan.

Received for publication 26 February 1990.

J. Clin. Invest.

(c) The American Society for Clinical Investigation, Inc. 0021-9738/90/07/0347/04 \$2.00

Volume 86, July 1990, 347-350
Argininemia (McKusick No. 20780), resulting from a deficiency in liver-type arginase, is a rare autosomal recessive disorder and is one of the heritable defects of ureagenesis. The clinical features are progressive mental impairment, progressive spasticity, growth retardation, and periodic episodes of hyperammonemia (12). We report here the first demonstration at the DNA level of mutations of the arginase gene in a patient with no consanguinity in the family. Discrete frameshift deletions were identified on two alleles.

\section{Methods}

Case. A markedly retarded girl with microcephaly, spastic tetraplagia, and intermittent convulsion was admitted to the hospital of Kurume University School of Medicine (Kurume, Japan). She was born to nonconsangineous, healthy parents after an uncomplicated pregnancy and delivery (13). At the age of $4 \mathrm{yr}$ and $2 \mathrm{mo}$ she was found to have hyperammonemia $(960 \mu \mathrm{g} / \mathrm{dl})$ and hyperargininemia (3.1-19.4 $\mathrm{mg} / \mathrm{dl})$. The diagnosis of angininemia was made in view of the elevated serum arginine concentration and practically nil activity of arginase of red blood cells (16 and $19 \mu \mathrm{mol} / \mathrm{h}$ per $\mathrm{g}$ hemoglobin, control; $3,716 \pm 2,236)$. Her father and mother were found to have low activities of arginase (1,103 and $1,440 \mu \mathrm{mol} / \mathrm{h}$ per $\mathrm{g}$ hemoglobin, respectively) and delayed patterns in arginine loading test; they were thought to be obligatory carriers.

Preparation of DNA and Southern blot analysis. Genomic DNAs of the patient and control were prepared from the transformed lymphocytes by infection of Epstein-Barr virus, as described (14). DNAs of the father and mother were prepared from peripheral blood lymphocytes by the established procedure (15). DNA was digested with restriction enzyme Eco RI or Hind III, separated by $0.7 \%$ agarose gel electrophoresis, and transferred to nitrocellulose filters. Hybridization was carried out according to Maniatis et al. (16) using ${ }^{32} \mathrm{P}$-labeled, full-length cDNA probe of human liver arginase $(8,10)$. The filters were washed and exposed for several days at $-70^{\circ} \mathrm{C}$.

Isolation and sequencing of genomic clones. The genomic library of the patient was prepared by ligation of a partial Eco RI digest of the patient DNA and Eco RI/Bam HI double-digest of bacteriophage $\lambda$ EMBL4 (Stratagene Co., La Jolla, CA) and packaging in vitro as described (17). The library was screened with ${ }^{32} \mathrm{P}$-labeled, full-length cDNA probe $(8,10)$. Phage DNAs of positive clones were subcloned into plasmid vector pUC18, and the nucleotide sequences of doublestranded plasmid subclones were determined by the dideoxynucleotide chain-termination method $(18,19)$ using synthetic oligonucleotide primers (9). Oligonucleotide primers were synthesized by a DNA synthesizer (model 381 A; Applied Biosystems Inc., Foster City, CA).

Polymerase chain reaction and polyacrylamide gel electrophoresis. Polymerase chain reaction (PCR) ${ }^{1}$ was performed for the regions of

1. Abbreviations used in the paper: $\mathrm{PCR}$, polymerase chain reaction. 
genomic DNAs containing the four- and one-nucleotide deletions. 1-2 $\mu \mathrm{g}$ of genomic DNA was used for amplification using Taq polymerase (Takara Shuzo, Kyoto, Japan) as described (20). Two sets of sense/antisense oligonucleotides were 5'-CCTGCCCTTTGCTGACATCCC$3^{\prime} / 5^{\prime}$-GTCTCCGCCCAGCACCA-3' to detect the four-nucleotide deletion and 5'-CCACGAGGAGGGGTGGA-3'/5'-CTCAAGCAGACCAGCCT $-3^{\prime}$ to detect the one-nucleotide deletion. The amplified fragments were subjected to 8 or $12 \%$ polyacrylamide gel electrophoresis for the four- or one-nucleotide deletion, respectively, and visualized by ethidium bromide staining. The sequence containing the first exon and the $5^{\prime}$ end region of the patient's genomic DNA was amplified by PCR using a set of primers 5'-TCAGAGATCTGGAGGAGGAAA- 3 '/ 5'-CCAGGAATTCAAAGAAAGACT-3', and was subcloned into pUC18 for sequencing.

\section{Results}

Southern blot analysis. The genomic DNAs from the patient and normal control were digested with Eco RI or Hind III, and analyzed on Southern blots. No difference in band pattern was found between the patient and control (Fig. 1). Thus, the lack of liver-type arginase activity in the patient was not the result of a large deletion or insertion in the arginase gene.

Identification of two deletion mutations. To define the mutation at the DNA level, we cloned and sequenced the genomic DNA from the patient. About $1.0 \times 10^{6}$ clones of the genomic library of the patient were screened using full-length human liver arginase cDNA as a probe. Eight positive clones were isolated but none contained the first exon and the $5^{\prime}$ end region. One was subcloned and the nucleotide sequences of the protein coding region and exon-intron junctions were determined. There was a 4-bp deletion at protein coding region $262-265$ or $263-266$ in exon 3 (Fig. $2 A$ ). The deletion should lead to a reading-frame shift after amino acid residue 87 and make a stop codon at residue 132 (Fig. $3 \mathrm{~A}$ ). To determine the sequence of the other allele, we amplified the lambda phage DNAs prepared from eight positive clones by PCR using the primers for the 4-bp deletion and subjected them to polyacrylamide gel electrophoresis. One clone that did not contain the 4-bp deletion was obtained. Sequencing of this clone showed a 1-bp deletion at protein coding region 77 or 78 in exon 2 (Fig. $2 B$ ). This deletion should lead to a reading-frame shift after
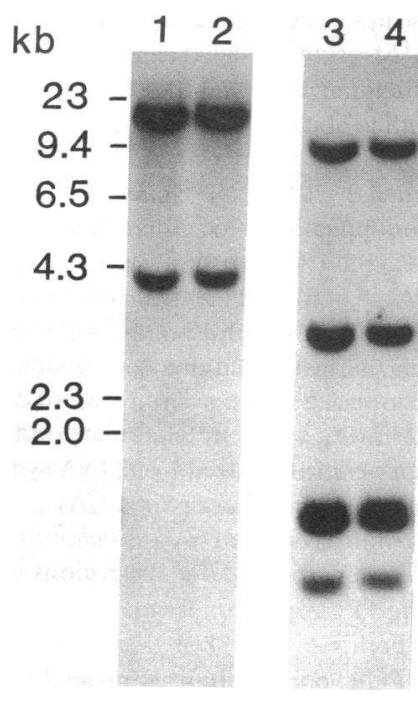

Figure 1. Southern blot analysis of genomic DNA from the patient (lanes 2 and 4) and normal control (lanes $I$ and 3). $10 \mu \mathrm{g}$ of DNA were digested with Eco RI (lanes $I$ and 2 ) or Hind III (lanes 3 and 4) and separated by electrophoresis in $0.7 \%$ agarose gel. Hybridization was carried out with ${ }^{32} \mathrm{P}$ labeled, full-length human liver arginase cDNA probe $(8$, 10). amino acid residue 26 and make a stop codon at residue 31 (Fig. 3 B).

To determine the sequence of the first exon and the $5^{\prime}$ end region of the patient's genomic DNA, we amplified the fragment by PCR and subcloned it into pUC18. Five clones were sequenced and there was no difference among these clones and one clone from a normal control. We concluded that the first exon and the 5 ' end region on two alleles of the patient had no mutation.

Confirmation of the mutations and analysis of DNA from the parents. To demonstrate that the two deletion mutations found in the patient's genomic library were not cloning artifacts, the fragments containing the region of the two mutations were amplified from the patient's genomic DNA by PCR and subjected to polyacrylamide gel electrophoresis. The 4-bp deletion was shown by separation of two bands of 145 and $141 \mathrm{bp}$ (Fig. $4 A$, lane 2). Similarly, the 1-bp deletion was shown by separation of two bands of 57 and 56 bp (Fig. $4 \mathrm{~B}$, lane 2). To confirm that these size differences of the bands resulted from the two deletion mutations, the amplified fragments were further digested with restriction enzyme Hinf I (for the 4-bp deletion) or Hae III (for the 1-bp deletion). The 4-bp deletion gave size differences of 71 and $67 \mathrm{bp}$, while the 1-bp deletion gave size differences of 23 and $22 \mathrm{bp}$, as expected from the sequence of relevant regions (data not shown).

Relevant portions of genomic DNA of her parents were amplified and analyzed. The father's DNA gave two bands of 145 and $141 \mathrm{bp}$ and the mother's DNA gave only one band of $145 \mathrm{bp}$ on the gel detecting the 4-bp deletion (Fig. $4 \mathrm{~A}$ ). On the other hand, on the plate detecting the 1-bp deletion, the mother's DNA contained two bands of 57 and 56 bp and the father's DNA contained one band of $57 \mathrm{bp}$ (Fig. $4 \mathrm{~B}$ ). Therefore, the father was heterozygous for the 4-bp deletion and the mother for the 1-bp deletion. This finding is in good accord with the expectation that the parents were obligatory carriers of argininemia. We conclude that the patient was a compound heterozygote, inheriting the allele with the 4-bp deletion from the father, and the allele with the 1-bp deletion from the mother.

\section{Discussion}

Biochemical and immunological analyses of argininemia have been reported. Spector et al. (21) analyzed three patients who were found to have immunoreactive arginase protein that was enzymatically inactive. Bernar et al. (22) reported findings in a patient with argininemia. The red blood cells showed no crossreacting material, as determined by Western transfer blot analysis. Since the cDNA and genomic clones were isolated, it was feasible to analyze materials at the genomic DNA or mRNA level. However, liver-type arginase is expressed only in the liver and in low amounts in red blood cells, hence an analysis at the mRNA level is difficult. Southern blot analysis of an argininemia patient was made (23), and there was no difference between findings in the patient and control. We examined the molecular basis for argininemia in a nonconsanguineous patient by constructing a genomic library and applying the PCR method. Our results revealed that argininemia in our patient was caused by two different deletion mutations that would lead to reading-frame shifts and to mutated and truncated enzyme proteins. 


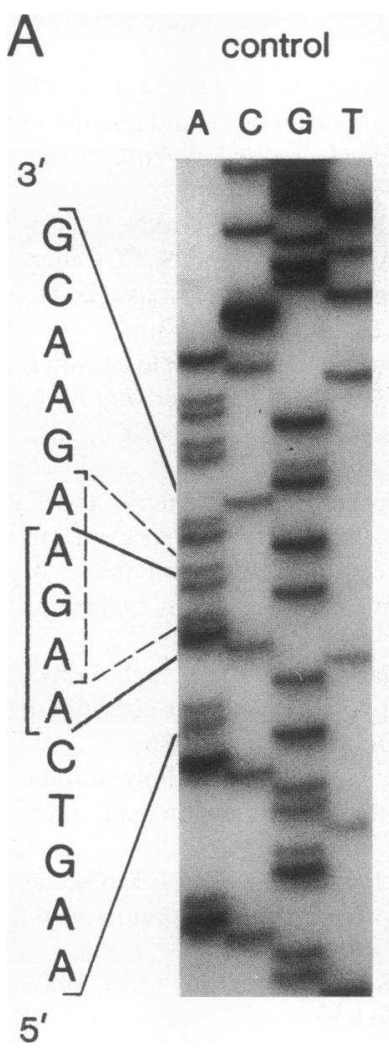

\section{patient}

A C G T

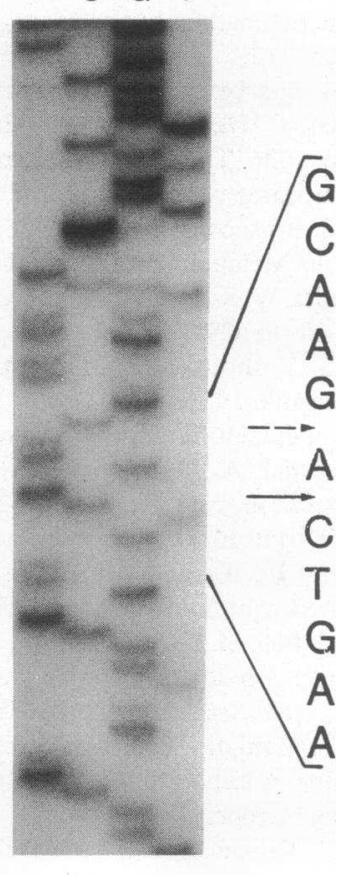

control

A C G T

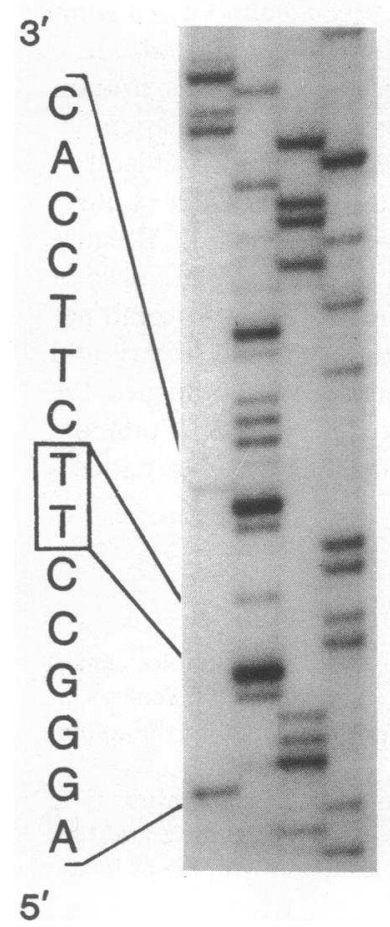

patient

A C G T

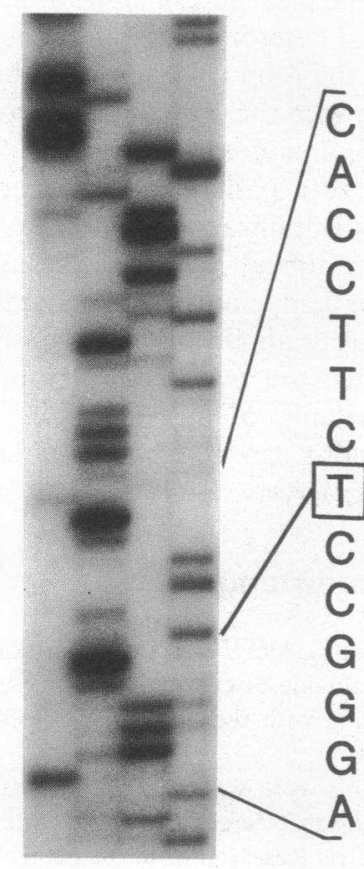

Figure 2. Sequence gels showing abnormality of patient's genomic DNA. The nucleotide sequence determination was performed as described in Methods. $A$, The sense strand nucleotide sequence (nucleotide 257-271) with 4-bp deletion is shown. Nucleotides of the two putative deletions are bracketed. Arrows indicate the corresponding positions in the patient. $B$, The antisense strand nucleotide sequence (nucleotide 69-84) with a 1-bp deletion in the patient is shown. Relevant nucleotides of the deletion are boxed.

The two deletion mutations were the 4-bp deletion at protein coding region 262-265 or 263-266 in exon 3 and the 1-bp deletion at protein coding region 77 or 78 in exon 2 . The regions of the deletions included short repeating sequences: AAGAAGAA for the 4-bp deletion and GAAGAAG for the 1-bp deletion (Fig. 3). A portion of repeating sequences can easily slip out during replication of DNA (24). The resulting mutated and truncated enzyme proteins presumably have no enzyme activity and would be rapidly degraded. Instead of the hybridization method we made use of polyacrylamide gel electrophoresis after PCR amplification of the gene. As shown in Fig. 4, the 4- and 1-bp deletions were evident. Thus, it seems
A

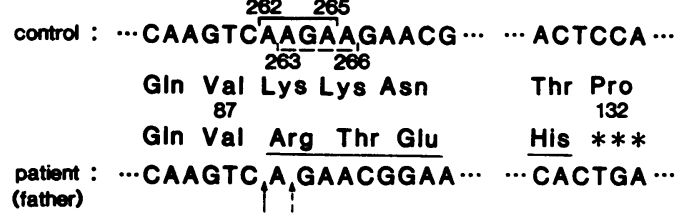

Figure 3. Mutations of arginase genes of two alleles in the patient. The region containing the 4-bp deletion $(A)$ and the 1-bp deletion $(B)$, and the position of the resulting stop codons are shown. Nucleotide number and amino acid residue are indicated beginning with the first residue of ATG and the initiator methionine of arginase cDNA, respectively (6). Brackets, arrows, and boxes are the same as in Fig. 2. The deduced amino acid sequences resulting from the frame-shifts are underlined.

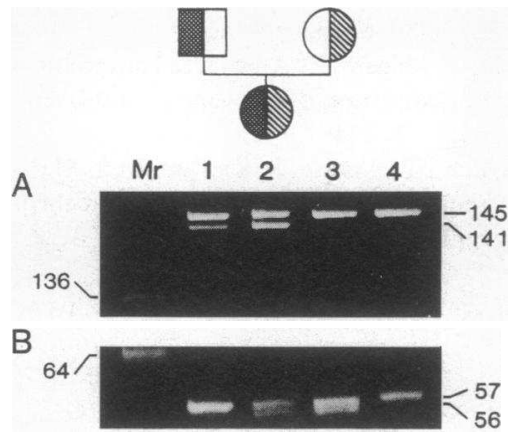

Figure 4. Pedigree and polyacrylamide gel electrophoresis of the amplified DNA fragments containing the 4- or 1-bp deletion in the patient. Relevant portions of the gels are shown. The PCR was used as described in Methods. $A$, The region containing the 4-bp deletion (nucleotide 156-300) was amplified, and the fragment was subjected to $8 \%$ polyacrylamide gel electrophoresis. $B$, The region containing the 1-bp deletion (nucleotide 58-114) was amplified, and the fragment was subjected to $12 \%$ polyacrylamide gel electrophoresis. The molecular size marker used was pUC18 digested with Alu I. Genomic DNA was from the father (lane 1), patient (lane 2), mother (lane 3), and control (lane 4). 
feasible to make a genetic diagnosis of these deletion mutants by making comparisons of the sizes of the amplified DNA fragments.

The present results show that the affected child was a compound heterozygote. The patient inherited the mutant allele with the 4-bp deletion from the father and the other mutant allele with the 1-bp deletion from the mother. Since argininemia is an autosomal recessive disorder, it would be difficult to analyze a patient of compound heterozygote by a strategy using amplification of each exon by the PCR method. Because it was difficult to obtain the mRNA of liver-type arginase of the patient, cloning or PCR amplification of CDNA would not be easily applicable. We constructed a genomic library and isolated the two different mutant genes. We confirmed the inheritance of this disorder. Carrier detection and prenatal diagnosis can now be made. DNA analyses of other patients are underway.

\section{Acknowledgments}

We thank Dr. F. Endo (Kumamoto University, Kumamoto, Japan) for valuable discussions, Dr. A. Tanoue (Kumamoto University) for assisting with the PCR, and $\mathrm{M}$. Ohara for comments on the manuscript.

This work was supported in part by a grant from the Ministry of Education, Science and Culture of Japan (62304042), and a grant for Pediatric Research from the Ministry of Health and Welfare of Japan.

\section{References}

1. Tomlinson, S., and R. G. Westall. 1964. Argininosuccinic aciduria, argininosuccinase and arginase in human blood cells. Clin. Sci. 26:261-269.

2. Herzfeld, A., and S. M. Raper. 1976. The heterogeneity of arginase in rat tissues. Biochem. J. 153:469-478.

3. Reddi, P. K., W. E. Knox, and A. Herzfeld. 1975. Types of arginase in rat tissues. Enzyme (Basel). 20:305-310.

4. Ratner, S., H. Morell, and E. Carvalho. 1960. Enzymes of arginase metabolism in brain. Arch. Biochem. Biophys. 91:280-289.

5. Glass, R. D., and W. E. Knox. 1973. Arginase isozymes of rat mammary gland, liver and other tissues. J. Biol. Chem. 248:57855789.

6. Kawamoto, S., Y. Amaya, K. Murakami, F. Tokunaga, S. Iwanaga, K. Kobayasi, T. Saheki, S. Kimura, and M. Mori. 1987. Complete nucleotide sequence of $\mathrm{CDNA}$ and deduced amino acid sequence of rat liver arginase. J. Biol. Chem. 262:6280-6283.

7. Ohtake, A., M. Takiguchi, Y. Shigeto, Y. Amaya, S. Kawamoto, and $M$. Mori. 1988. Structural organization of the gene for rat livertype arginase. J. Biol. Chem. 263:2245-2249.

8. Haraguchi, Y., M. Takiguchi, Y. Amaya, S. Kawamoto, I. Matsuda, and M. Mori. 1987. Molecular cloning and nucleotide sequence of cDNA for human liver arginase. Proc. Natl. Acad. Sci. USA. 84:412-415.

9. Takiguchi, M., Y. Haraguchi, and M. Mori. 1988. Human liver- type arginase gene: structure of the gene and analysis of the promoter region. Nucleic Acids Res. 16:8789-8802.

10. Haraguchi, Y., M. Takiguchi, I. Matsuda, and M. Mori. 1988. Sequence heterogeneity of human liver arginase cDNA and restriction fragment length polymorphism of the gene locus. Jpn. J. Hum. Genet. 33:305-313.

11. Sparkes, R. S., G. J. Dizike, I. Klisak, W. W. Grody, T. Mohandas, C. Heinzmann, S. Zollman, A. J. Lussis, and S. D. Cederbaum. 1986. The gene for human liver arginase (ARG1) is assigned to chromosome band 6q23. Am. J. Hum. Genet. 39:186-193.

12. Brusilow, S. W., and A. L. Horwich. 1989. Urea cycle enzymes. In The Metabolic Basis of Inherited Disease. C. R. Scriver, A. L. Beaudet, W. S. Sly, and D. Valle, editors. McGraw-Hill Book Co., Inc., New York. 629-663.

13. Yoshino, M., K. Kubota, I. Yoshida, T. Murakami, and F. Yamashita. 1983. Argininemia: report of a new case and mechanisms of orotic aciduria and hyperammonemia. In Urea Cycle Disease. A Lowenthal, A. Mori, and B. Marescau, editors. Plenum Publishing Corporation, New York. 121-125.

14. Matsuda, I., J. Yamamoto, N. Nagata, N. Ninomiya, I. Akaboshi, H. Ohtsuka, and T. Katsuki. 1977. Lysosomal enzyme activities in cultured lymphoid cell lines. Clin. Chim. Acta. 80:483-486.

15. Bell, G. I., J. H. Karam, and W. I. Rutter. 1981. Polymorphic DNA region adjacent to the $5^{\prime}$ end of the human insulin gene. Proc. Natl. Acad. Sci. USA. 78:5759-5763.

16. Maniatis, T., E. F. Fritsch, and J. Sambrook. 1982. Molecular Cloning: A Laboratory Manual. Cold Spring Harbor Laboratory, Cold Spring Harbor, NY. 387-389.

17. Takiguchi, M., T. Murakami, S. Miura, and M. Mori. 1987. Structure of the rat ornithine carbamoyltransferase gene, a large, $\mathrm{X}$ chromosome-linked gene with an atypical promoter. Proc. Natl. Acad. Sci. USA. 84:6136-6140.

18. Sanger, F., S. Nicklen, and A. R. Coulson. 1977. DNA sequencing with chain-terminating inhibitors. Proc. Natl. Acad. Sci. USA. 74:5463-5467.

19. Hattori, M., and Y. Sakaki. 1986. Dideoxy sequencing method using denatured plasmid templates. Anal. Biochem. 152:232-238.

20. Saiki, R. K., S. Scharf, F. Faloona, K. B. Mullis, G. T. Horn, H. A. Erlich, and N. Arnheim. 1985. Enzymatic amplification of $\beta$ globin genomic sequences and restriction site analysis for diagnosis of sickle cell anemia. Science (Wash. DC). 230:1350-1354.

21. Spector, E. B., S. C. H. Rice, and S. D. Cederbaum. 1983 Immunologic studies of arginase in tissues of normal human adult and arginase-deficient patients. Pediatr. Res. 17:941-944.

22. Bernar, J., R. A. Hanson, R. Kern, B. Phoenix, K. N. F. Shaw, and S. D. Cederbaum. 1986. Arginase deficiency in a 12 -year-old boy with mild impairment of intellectual function. J. Pediatr. 108:432435.

23. Grody, W. W., C. Argyle, R. M. Kern, G. J. Dizikes, E. B. Spector, A. D. Strickland, D. Klein, and S. D. Cederbaum. 1989. Differential expression of the two human arginase genes in hyperargininemia. Enzymatic, pathologic, and molecular analysis. J. Clin. Invest. 83:602-609.

24. Gibbs, R. A., P.-N. Nguyen, L. J. McBride, S. M. Koepf, and C. T. Caskey. 1989. Identification of mutations leading to LeschNyhan syndrome by automated direct DNA sequencing of in vitro amplified cDNA. Proc. Natl. Acad. Sci. USA. 86:1919-1923. 